\title{
ОЦЕНКА СТОЙКОСТИ БЕТОНА К ВОЗДЕЙСТВИЮ ВЫСОКИХ ТЕМПЕРАТУР НА ОСНОВЕ ГОСТ 29167-2020
}

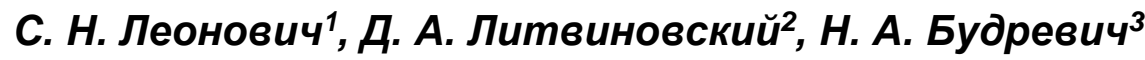 \\ 1 Д. т. н., nрофрессор, декан строительного факультета БНТУ, Минск, Беларусь, e-mail: leonovichsn@tut.by \\ 2 Главный инженер 000 «ИнжСпецСтройПроект», Минск, Беларусь, е-таil: 7200743@gmail.com \\ ${ }^{3}$ Инженер научно-исследовательской лаборатории промышленного и гражданского строительства, \\ аспирант кафедры «Строительные материалы и технология строительства» БНТУ, Минск, Беларусь, e-mail: nellibudrevich@yandex.by
}

\section{Рефрерат}

На основе анализа экспериментальных исследований предложены критерии хрупкости для высокопрочного бетона при высоких температурах и рекомендованы их пороговые значения, которые определяются по разработанной методике для бетона при $t=20{ }^{\circ} \mathrm{C}$. Критерии хрупкости для высокопрочного бетона при высоких температурах для эксплуатируемых конструкций определяются на основе зависимости $E$ и $K_{\text {IC }}$ от поверхностной твердости $H$. На основании полученных экспериментальных данных предложено значение поверхностной твердости (при $t=20^{\circ} \mathrm{C}$ ) высокопрочного бетона $H>450 \mathrm{MПа,} \mathrm{при} \mathrm{нагреве} \mathrm{которого} \mathrm{будет} \mathrm{происходить} \mathrm{хрупкое} \mathrm{разрушение.}$

Ключевые слова: высокопрочный бетон, хрупкость, трещиностойкость, предел прочности, вязкость разрушения, стойкость, высокие температуры.

\section{ASSESSMENT OF CONCRETE RESISTANCE TO HIGH TEMPERATURES BASED ON STATE STANDARD 29167-2020}

\section{Abstract}

\section{S. N. Leonovich, D. A. Litvinovsky, N. A. Budrevich}

On the basis of the analysis of experimental studies, brittleness criteria for high-strength concrete at high temperatures are proposed and their threshold values are recommended, which are determined by the developed method for concrete at $t=20^{\circ} \mathrm{C}$. The brittleness criteria for high-strength concrete at high temperatures for operating structures are determined on the basis of the dependence of $E$ and $K_{\mathrm{I}}$ on the surface hardness $H$. Based on the experimental data obtained, the value of the surface hardness (at) of high-strength concrete $H>450 \mathrm{MPa}$ is proposed, when heated, brittle fracture will occur.

Keywords: high-strength concrete, fragility, crack resistance, ultimate strength, fracture toughness.

Для анализа хрупкости бетонов обычной прочности в настоящее время используют формулу Жукова В. В. для расчета хрупкого разрушения $\mathrm{F}$ :

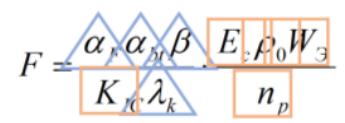

где $\alpha_{F}$ - коэффицииент пропорциональности:

$$
\alpha_{F}=1,16 \cdot 10^{-2} \mathrm{Bm} \cdot \mathcal{M}^{5 / 2} \cdot \kappa 2^{-1} \text {; }
$$

$\alpha_{\text {ие }}$ - коэффрициент температурной деформации расширения бетона, ${ }^{\circ} \mathrm{C}^{-1}$;

$\lambda_{k}$ - коэффрициент теплопроводности бетона, Вт/(м. $\left.{ }^{\circ} \mathrm{C}\right)$;

$\beta$ - коэффициент изменения модуля упругости бетона при нагреве;

$E$ - модуль упругости бетона при нормальных условиях, МПа;

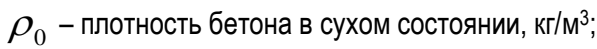

$n_{p}$ - общая пористость бетона, \%;

$K_{I C}-$ критический коэффициент интенсивности напряжения, $\mathrm{MH} / \mathrm{M}^{-3 / 2}$

$W_{\ni}$ - объемная эксплуатационная влажность бетона, $\mathrm{m}^{3} / \mathrm{M}^{3}$;

- текущие значения Литвиновского Д. А., Леоновича С. Н.;

- параметры Жукова В. В. [1, 2].
Критерий хрупкости $F$ на основе текущих (для температур 20, $\left.100,200,300,400,500,600,700^{\circ} \mathrm{C}\right)$ значений $K_{I C}, E, \rho_{0}, W_{\ni}$, $n_{p}$, полученных автором экспериментально, графически представлен на рисунке 1.

На основе анализа экспериментальных исследований предложены критерии хрупкости для высокопрочного бетона при высоких температурах и рекомендованы их пороговые значения (таблица 1), которые определяются по разработанной методике для бетона при $t=20^{\circ} \mathrm{C}$.

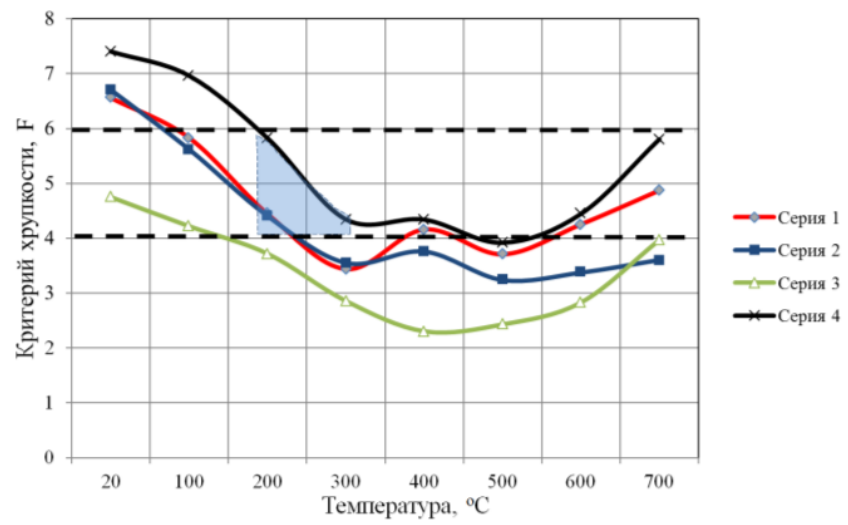

Рисунок 1 - Значения критерия хрупкости $F$ для серий бетонных образцов 1, 2, 3,4 [1, 2]

Таблица 1 - Рекомендуемые значения критериев хрупкости при нормальной температуре (при $t=20^{\circ} \mathrm{C}$ )

\begin{tabular}{|c|c|c|}
\hline$K_{I C}, \mathrm{MH} / \mathrm{M}^{-3 / 2}$ & $G_{i}, \mathrm{H} / \mathrm{M}$ & $l_{c h}, \mathrm{M}$ \\
\hline$>0.8$ & $>14$ & $\approx 0,03$ \\
\hline
\end{tabular}


Вестник Брестского государственного технического университета. 2021

Значения критериев коэффициента интенсивности напряжения $K_{I C}$, энергия разрушения, критическая длина трещины определяются по формулам $(2,3,4)$ :

$$
\begin{gathered}
K_{I C}=\frac{F_{c}}{b \cdot h^{1 / 2}}\left[\begin{array}{c}
18,3 \cdot\left(\frac{a}{h}\right)^{1 / 2}-430 \cdot\left(\frac{a}{h}\right)^{3 / 2}+3445 \cdot\left(\frac{a}{h}\right)^{5 / 2}- \\
-11076 \cdot\left(\frac{a}{h}\right)^{7 / 2}+12967 \cdot\left(\frac{a}{h}\right)^{9 / 2}
\end{array}\right], \\
G_{i}=\frac{K_{I C}^{2}}{E}, \\
l_{c}=\frac{G_{i} E}{f_{c t m}^{2}},
\end{gathered}
$$

где $F_{c}$ - нагрузка, при которой происходит разрушение образца;

$E-$ модуль упругости,

$f_{c t m}$ - прочность бетона на растяжение.

Для эксплуатируемых конструкций разработана специальная комплексная многопараметричная методика на основе испытания бетона методом упругого отскока (прибор ИМ-1Б). Прибор ИПМ-1Б внедрен автором на базе НИЛ ПГС БНТУ с лабораторией контактнодинамических методов контроля Института прикладной физики НАН Беларуси и внесен в реестр средств измерений.

Критерии хрупкости для высокопрочного бетона при высоких температурах для эксплуатируемых конструкций определяются на основе

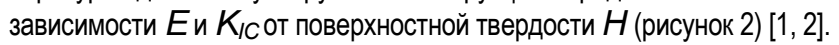

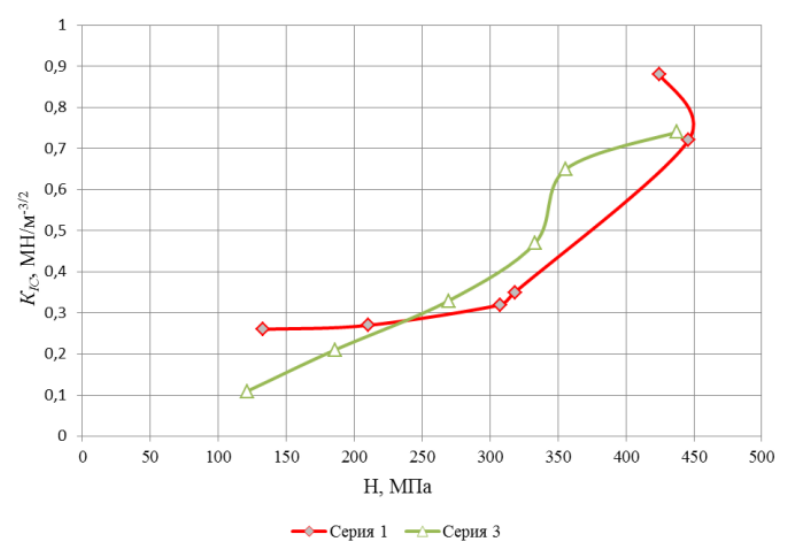

a)

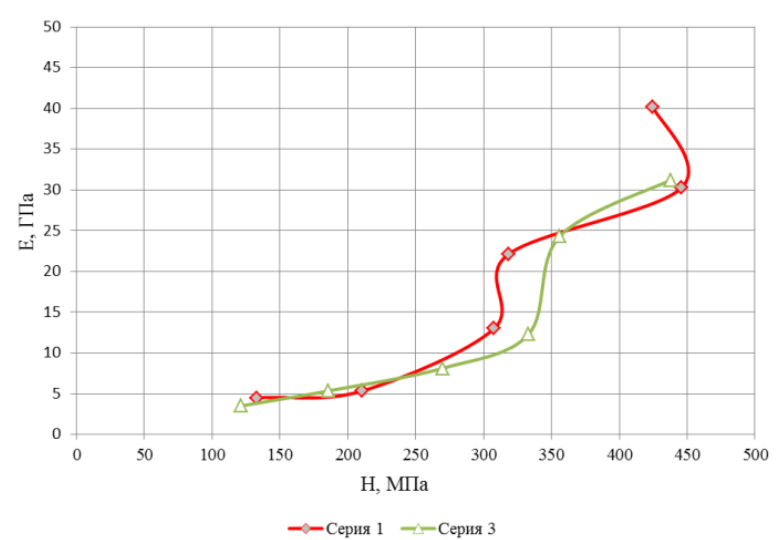

б)

Рисунок 2 - Зависимость модуля упругости $E$ (а) и $K_{\text {IC }}$ от поверхностной твердости $H$ (б)
На основании полученных экспериментальных данных предложено значение поверхностной твердости (при $t=20^{\circ} \mathrm{C}$ ) высокопрочного бетона $H>450 \mathrm{MПа,} \mathrm{при} \mathrm{нагреве} \mathrm{которого}$ будет происходить хрупкое разрушение.

Рассмотрены результаты экспериментальных исследований высокопрочного сталефибробетона, подвергнутого высокотемпературному нагреву. Дисперсное армирование в экспериментальных исследованиях существенно повлияло только на коэффицциент интенсивности напряжений при поперечном сдвиге.

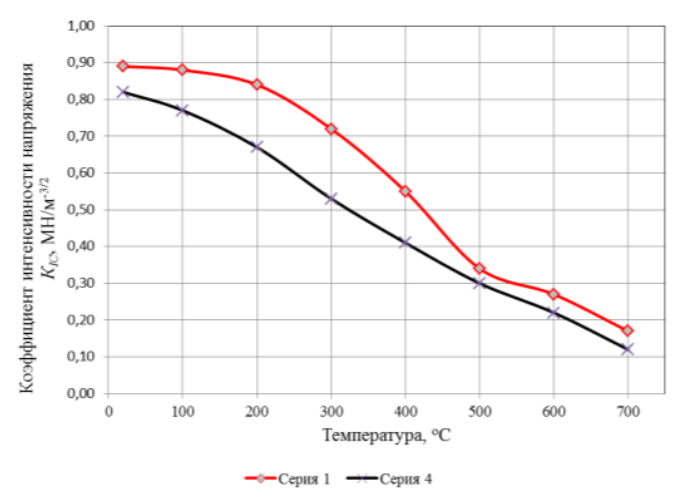

a)

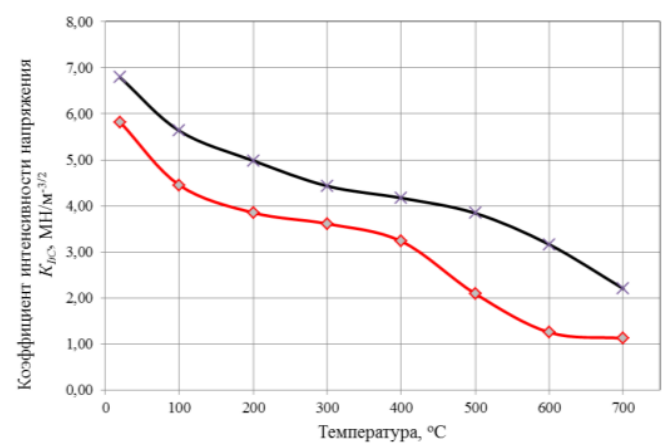

$\rightarrow$ Серия 1 - Серия 4

б)

Рисунок 3 - Изменение коэффициентов интенсивности напряжения при нормальном отрыве $K_{I C}$ (а) и поперечном сдвиге $K_{\text {IIC }}$ (б) высокопрочного бетона (серия 1) и сталефибробетона (серия 4)

Критерии хрупкости для высокопрочного бетона при высоких температурах для эксплуатируемых конструкций определяются на основе зависимости $E$ и $K_{I C}$ от поверхностной твердости $H$ (рисунок 3) [1, 2].

Разработанный межгосударственный стандарт ГОСТ 29167-2020 «Бетоны. Методы определения характеристик трещиностойкости (вязкости разрушения) при статическом нагружении» [7] распространяется на бетоны всех видов, применяемых в строительстве, и устанавливает методы их испытаний для определения силовых и энергетических характеристик трещиностойкости при статическом кратковременном нагружении.

Устанавливаются методы определения характеристик трещиностойкости путем равновесных и неравновесных механических испытаний.

Равновесные испытания на стадии локального деформирования образца характеризуются обеспечением адекватности изменения внешних сил внутренним усилиям сопротивляемости материала с соответствующим статическим развитием магистральной трещины.

Неравновесные испытания характеризуются потерей устойчивости процесса десормирования образца в момент локализации деформации по достижении максимальной нагрузки, с соответствующим динамическим развитием магистральной трещины.

Для определения характеристик трещиностойкости испытывают образцы с начальным надрезом. При равновесных испытаниях 
записывают диаграмму $F-V$; при неравновесных испытаниях фиксируют значение $F_{c}^{*}$.

Допускается проведение равновесных испытаний с фиксацией текущих размеров развивающейся магистральной трещины $\left(a_{i j}\right)$ и соответствующих значений прилагаемой нагрузки $\left(F_{i j}\right)$.

По результатам испытаний определяют следующие основные силовые - в терминах коэфффициентов интенсивности напряжений $(K)$, энергетические - в терминах удельных энергозатрат $(G)$ и джей-интеграла $(J)$ характеристики трещиностойкости: $K_{C}$, $\boldsymbol{K}_{C}^{*}, K_{i}, G_{F}, G_{i}, G_{c e}, J_{i}, \chi_{F}^{c}$.

Новым в актуальной редакции ГОСТ 29167 является то, что определяемые по настоящему стандарту характеристики трещиностойкости (наряду с другими характеристиками механических свойств) применяют для оценки стойкости к воздействию высоких температур используя силовые критерии механики разрушения - коэффициенть интенсивности напряжений при нормальном отрыве КІс.

Предлагаемый подход состоит в следующем:

1. Определяется $K_{I C}$ бетона призмы по равновесной схеме [6, 7].

2. Полученные в процессе равновесных исследований две половинки призмы надрезаются по середине и испытываются по неравновесной схеме (рис. 4) с расчетом $K_{I C}[3,4,5]$.

3. Получившиеся при испытаниях 4 кубика 100×100×100 мм надрезаются с двух сторон. В результате испытаний на нормальный отрыв получаем четыре значения $K_{I C}[6,7]$.

4. Полученные при фрагментации 4 кубов 8 бетонных пластин 100x100x50 мм испытываются по схеме (рис. 5), производится расчет восьми значений $K_{\text {IIC }}[3,4,5]$.

Внесение в ГОСТ 29167-2020 метода отрыва со скалыванием (рис. 6) определять коэффициент интенсивности напряжений при нормальном отрыве бетона эксплуатируемых конструкций.

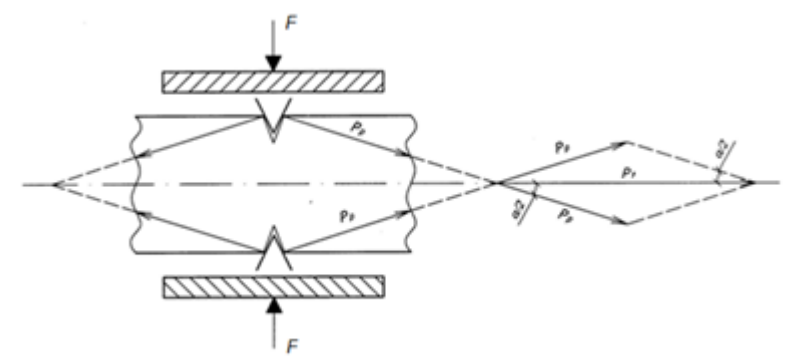

Рисунок 4 - Схема нагружения образца для расчета $K_{I C}$

$$
K_{I C}=\frac{F_{c}}{b\left(h-2 \alpha_{c r}\right)} \cdot \frac{(\cos \alpha / 2-f \sin \alpha / 2)}{(\cos \alpha / 2+f \sin \alpha / 2)} \cdot \sqrt{\frac{2 \pi k d_{\max }}{(1+v)(1-2 v)}},
$$

где $F_{c}$ - разрушающая нагрузка, $\mathrm{MH}$;

$b$ - ширина образца, м;

$h$ - высота образца, м;

$a$ - глубина надреза (паза), м;

$\alpha$ - угол клиновидного паза, град.;

$f$ - коэффициент трения между поверхностями паза и клина; $\pi$ - математическая константа, равная 3,14 ;

$d_{\max }$ - максимальный размер заполнителя, м, при

$d_{\max } \geq 0,02 \mathrm{~m}, k=1,2$;

$v$-коэффициент Пуассона.

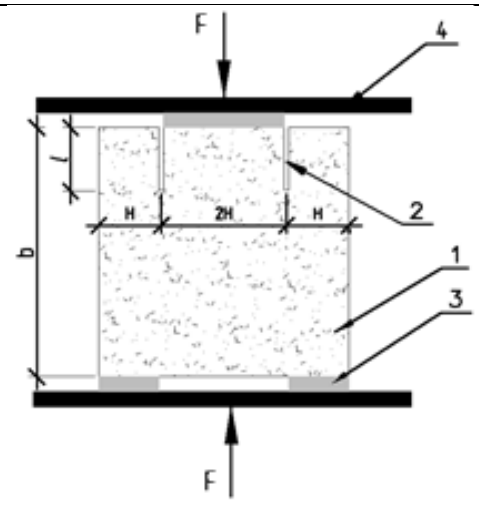

Рисунок 5 - Испытания на поперечный сдвиг

$$
K_{I I C}=\frac{F_{c}}{2 t H} \sqrt{l \cdot Y(l, b)},
$$

где $F_{c}$ - нагрузка, при которой происходит разрушение, $\mathrm{H}$;

$t$ - толщина изделия, м;

$H$ - ширина плеча изделия, м;

$l$ - глубина надреза, м;

$Y(l, b)$ - поправочный коэффрициент (определяется по таблице 1).

Таблица 2 - Значения поправочного коэфффициента $Y(l, b)$

\begin{tabular}{|c|c|c|c|}
\hline \multirow{2}{*}{$/ / b$} & \multicolumn{3}{|c|}{$H$} \\
\cline { 2 - 4 } & 0,037 & 0,025 & 0,012 \\
\hline 0,1 & 1,2 & 1,1 & 1,07 \\
\hline 0,2 & 1,26 & 0,99 & 0,9 \\
\hline 0,3 & 1,3 & 0,95 & 0,76 \\
\hline 0,4 & 1,32 & 0,95 & 0,65 \\
\hline
\end{tabular}
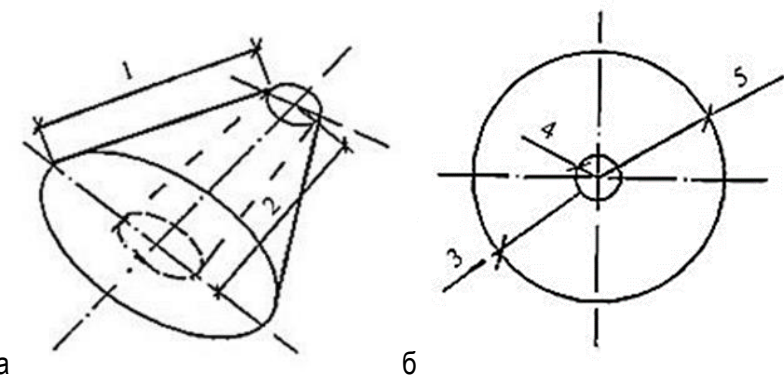

б

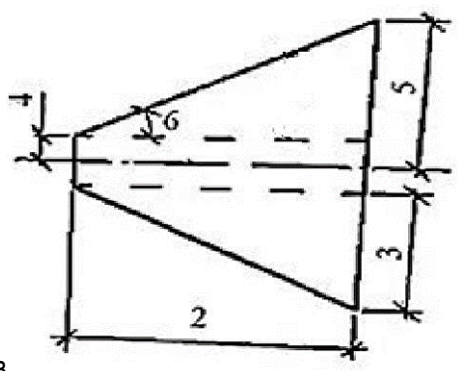

а - в аксонометрии, б - вид спереди, в - вид сбоку

1 - длина образующей конуса разрушения $l ; 2$ - длина шпура $h$; 3 - разница между максимальным радиусом конуса разрушения и радиусом шпура $R ; 4$ - радиус шпура $r_{0} ; 5$-максимальный радиус конуса разрушения $r_{\max } ; 6$-угол между образующей конуса разрушения и стороной шпура $\alpha$.

Рисунок 6 - Схема усеченного конуса вырыва: 


$$
K_{I C}=\frac{3 P\left[\cos ^{2}(90-\alpha)-\sin ^{2}(90-\alpha)\right]}{2 \pi h^{2}\left(1+\frac{r_{0}}{r_{0}+h \cdot \operatorname{tg} \alpha}\right)} \cdot \sqrt{2 \pi l}\left[\frac{0.8}{\left(\frac{R}{l}\right)^{3}-1}+0.7\right],(7)
$$

где $P$-усилие вырыва, МН;

$\alpha$ - угол между образующей конуса разрушения и стороной

шпура; $\alpha=\operatorname{arctg}\left(\frac{R}{h}\right)$.

Преимуществом предложенной процедуры испытаний является то, что на одной бетонной призме (не на образцах-близнецах) мы получаем: $K_{/ C}$ в результате равновесных испытаний призмы 100x100x400 мм на 3-х точечный изгиб, два значения $K_{I C}$ при раскалывании 2-х половинок призмы 100х100х200 мм, четыре значения $K_{I C}$ при испытании 4-х кубов 100×100×100 мм с боковыми надрезами на сжатие, инициируя нормальный отрыв, и восемь значений $K_{\text {IIC }}$, инициируя в бетонных пластинах 100х100х50 мм поперечный сдвиг. При этом мы сравниваем 1 значение $K_{I C}$ равновесных испытаний, с 2-мя и 4-мя значениями $K_{I C}$ по двум различным методикам неравновесных испытаний, и все это производится буквально на одном образце бетона, что также исключает погрешность от использования образцов-близнецов.

Восемь значений $K_{\text {II }}$ (рисунок 5) являются также хорошей статистической основой для достоверной оценки коэффициента интенсивности напряжений при поперечном сдвиге, а также надежной базой для обоснования соотношения $\frac{K_{I I C}}{K_{I C}}$.

\section{Список цитированных источников}

1. Леонович, С. Н. Прочность, трещиностойкость и долговечность конструкционного бетона при воздействии высоких температур / С. Н. Леонович, Д. А. Литвиновский, Л. В. Ким. - Владивосток : Дальневост. федер. ун-т, 2015. - 148 с.

2. Литвиновский, Д. А. Прочность, трещиностойкость и долговечность конструкционного бетона при воздействии высоких температур / Д. А. Литвиновский // Прочность, трещиностойкость и долговечность конструкционного бетона при температурных и коррозионных воздействиях: в 2 ч. / С. Н. Леонович [и др.] ; под ред. С. Н. Леоновича. - Минск, 2016. - Ч. 1. - Гл. 1. - С. 12-160.
3. Способ определения критического коэффицциента интенсивности напряжения высокопрочного бетона: пат. ВY 16193 / С. Н. Леонович, Д. А. Литвиновский. - Опубл. 30.08.2012.

4. Способ определения критического коэффициента интенсивности напряжения высокопрочного бетона: пат. ВY 16194 / С. Н. Леонович, Д. А. Литвиновский. - Опубл. 30.08.2012.

5. Способ определения критического коэффициента интенсивности напряжения высокопрочного бетона: пат. ВY 19170 / С. Н. Леонович, Д. А. Литвиновский. - Опубл. 30.06.2015.

6. Бетоны. Методы определения характеристик трещиностойкости (вязкости разрушения) при статическом нагружении: ГОСТ 29167-91. - Москва : Научно-исследовательским, проектно-конструкторским и технологическим институтом бетона и железобетона (НИИЖБ), 1992. - 14 с.

7. Бетоны. Методы определения характеристик трещиностойкости (вязкости разрушения) при статическом нагружении: ГОСТ 29167-2020.

\section{References}

1. Leonovich, S. N. Prochnost', treshchinostojkost' i dolgovechnost' konstrukcionnogo betona pri vozdejstvii vysokih temperatur / S. N. Leonovich, D. A. Litvinovskij, L. V. Kim. - Vladivostok : Dal'nevost. feder. un-t, 2015. - $148 \mathrm{~s}$.

2. Litvinovskij, D. A. Prochnost', treshchinostojkost' i dolgovech-nost' konstrukcionnogo betona pri vozdejstvii vysokih temperatur / D. A. Litvinovskij // Prochnost', treshchinostojkost' i dolgovechnost' konstrukcionnogo betona pri temperaturnyh i korrozionnyh vozdejstviyah: v 2 ch. / S. N. Leonovich [i dr.] ; pod red. S. N. Leonovicha. Minsk, 2016. - CH. 1. - Gl. 1. - S. 12-160.

3. Sposob opredeleniya kriticheskogo koefficienta inten-sivnosti napryazheniya vysokoprochnogo betona: pat. BY 16193 / S. N. Leonovich, D. A. Litvinovskij. - Opubl. 30.08.2012.

4. Sposob opredeleniya kriticheskogo koefficienta inten-sivnosti napryazheniya vysokoprochnogo betona: pat. BY 16194 / S. N. Leonovich, D. A. Litvinovskij. - Opubl. 30.08.2012.

5. Sposob opredeleniya kriticheskogo koefficienta inten-sivnosti napryazheniya vysokoprochnogo betona: pat. BY 19170 / S. N. Leonovich, D. A. Litvinovskij. - Opubl. 30.06.2015.

6. Betony. Metody opredeleniya harakteristik treshchinostojkosti (vyazkosti razrusheniya) pri staticheskom nagruzhenii: GOST 29167-91. Moskva : Nauchno-issledovatel'skim, proektno-konstruktorskim i tekhnologicheskim institutom betona i zhelezobetona (NIIZHB), 1992. - $14 \mathrm{~s}$.

7. Betony. Metody opredeleniya harakte-ristik treshchinostojkosti (vyazkosti razrusheniya) pri staticheskom nagruzhenii: GOST 29167-2020.

Материал поступил в редакцию 06.05.2021 